\title{
Corrigendum
}

\section{Loss of H3K27 tri-methylation is a diagnostic marker for malignant peripheral nerve sheath tumors and an indicator for an inferior survival}

Arjen HG Cleven, Ghadah A Al Sannaa, Inge Briaire-de Bruijn, Davis R Ingram, Matt van de Rijn, Brian P Rubin, Maurits W de Vries, Kelsey L Watson, Kelia E Torres, Wei-Lien Wang, Sjoerd G van Duinen, Pancras CW Hogendoorn, Alexander J Lazar and Judith VMG Bovée

Modern Pathology (2016) 29, 1113; doi:10.1038/modpathol.2016.103

Correction to: Modern Pathology advance online publication, 18 March 2016; doi:10.1038/ modpathol.2016.45
In this paper, the name of the ninth author is incorrect; the correct name Keila E Torres. 